\title{
Beneficial effects of adrenergic blockade in patients with subarachnoid haemorrhage
}

\author{
P WALTER, G NEIL-DWYER, J M CRUICKSHANK
}

\begin{abstract}
A total of 148 patients presenting within 48 hours of subarachnoid haemorrhage were assigned at random to receive standard management only or standard management and treatment with the adrenergic-blocking agents propranolol and phentolamine (or propranolol alone) for three weeks. One hundred and thirty-four patients completed the study. Assessment at four weeks showed a strong trend for less neurological deficit in the treated group, almost statistically significant $(p=0.053)$ in the women. During the first month the treated group suffered fewer episodes of clinical deterioration consistent with cerebral arterial spasm: thus more treated patients underwent operation and those who did had a better outcome $(\mathbf{p}=\mathbf{0} \cdot 030)$.

At one year fewer were dead or disabled (unable to work) in the treated group; a significant difference for women $(p=0.030)$. Possible mechanisms for these actions may include a reduction in pulmonary oedema, prevention of myocardial infarcts, a reduction in plasma renin activity, and a reduction in cerebral oxygen requirements.

It is concluded that early adrenergic blockade benefits patients (particularly women) with subarachnoid haemorrhage for up to one year in terms of lesser neurological deficit. Beta-blockade rather than alpha-blockade
\end{abstract}

Neurosurgical Department, London Hospital, London E1 1BB $P$ WALTER, BSC, FRCS, senior registrar

Department of Neurosurgery, Brook General Hospital, London SE18 4LW

G NEIL-DWYER, MS, FRCS, consultant neurosurgeon

Imperial Chemical Industries Limited, Pharmaceuticals Division, Macclesfield, Cheshire

J M CRUICKSHANK, DM, MRCP, medical adviser appears to be the useful component. A randomised, blind extension of the present study using long-acting propranolol and placebo has shown a significant $(p=0.026)$ decrease in deaths and significantly $(p=0.003)$ fewer poor results in the treatment group.

\section{Introduction}

The advances in management of subarachnoid haemorrhage due to aneurysm have been considerable during recent years. The timing of operation and the introduction of the operating microscope and microsurgical techniques have improved the results of surgery. Nevertheless, the problems of arterial spasm remain, both as a direct complication of haemorrhage and as a postoperative problem. Fear of postoperative spasm often delays operation, thereby exposing the patient to the risk of recurrent haemorrhage for several additional days. Despite the introduction of antifibrinolytic agents risk of rebleeding during the first two weeks is appreciable. Any treatment reducing the risk of spasm would therefore improve results, both directlyby reducing the rate of the complication-and indirectly-by making early surgery safer. Many agents have been implicated in the aetiology of cerebrovascular spasm after subarachnoid haemorrhage. Under experimental conditions several biological agents induce contraction of cerebral vessels. These include blood, cerebrospinal fluid from patients with spasm, catecholamines, serotonin, and some prostaglandins. ${ }^{1-3}$ More recently the breakdown products of red cells have been suggested as a cause. ${ }^{4}$

In view of $(a)$ the high output of catecholamines, sometimes comparable to levels seen in phaechromocytoma, ${ }^{5}$ in subarachnoid haemorrhage; (b) cerebral angiographic findings in phaeochromocytoma ${ }^{6}$ similar to those seen in spasm associated with subarachnoid haemorrhage; $(c)$ evidence of adrenergic nerve fibres associated with cerebral vessels ${ }^{7}$; and $(d)$ the beneficial effects of propranolol on the electrocardiographic changes and focal myocardial necrosis associated with subarachnoid haemorrhage ${ }^{8}$ we decided to set up a prospective randomised placebo-controlled study of treatment of subarachnoid haemorrhage with a combination of alpha-blockade and betablockade. 


\section{Patients and methods}

All patients aged 15-65 admitted to the neurosurgical unit at the Brook General Hospital within 48 hours of a subarachnoid haemorrhage confirmed by lumbar puncture were considered for the study. Patients who were already moribund were excluded, as were known hypertensives, patients receiving antihypertensive medication, those with previous myocardial infarction or obstructive airways disease, and those already receiving adrenergic-blocking agents.

A total of 148 patients were admitted to the trial; the first 118 patients in this randomised, double-blind, between-patient study received either phentolamine $20 \mathrm{mg}$ three-hourly and propranolol (Inderal) $80 \mathrm{mg}$ eight-hourly or identical placebo tablets. The remaining 30 patients (randomised by day of admission) received treatment with propranolol $80 \mathrm{mg}$ three times daily or no drug. Six patients (under one specialist) - two in the treated group and four controls-were also treated with tranexamic acid. Eighteen patients (six in the treated group, 12 controls) received dexamethasone. Anticonvulsants were given to patients having seizures and prophylactically after craniotomy. All patients had standard management-that is, codeine phosphate for pain and adequate intake of calories and fluids. The drugs were administered orally; when patients were unable to swallow the tablets were crushed, dissolved, and administered via a nasogastric tube. The treatment was continued for three weeks. Only the anasthetists had access to the code.

Computed tomography was performed within 24 hours of admission. Carotid angiography was performed in most cases at 3-5 days but was deferred if the patient was clearly unfit; two patients who survived never underwent angiography. Vertebral angiography was performed where indicated, usually at a different time from the carotid angiogram.

If no anatomical bleeding lesion was found, or the lesion was deemed inoperable, the patient was maintained on a conservative regimen with bed rest for four weeks. Most operations were carried out within eight to 20 days. Check angiography was performed one week after surgery and the patient mobilised thereafter.

At the time of admission a neurological assessment of the patient was carried out and a grading made on the basis of this examination as follows: 1-alert, no abnormal neurological signs; 2 -alert, minor neurological signs; 3-alert, major signs; 4-drowsy, minor signs; 5-drowsy, major signs; 6-comatose. Further assessments were made on days four, eight, 12,20 , and 28 . The gradings indicated in this report are those at admission and on the 28th day. A final assessment of surviving patients was made at one year. Patients who had returned to work or those who were capable of working without appreciable neurological deficit, were regarded as having good results. Those with appreciable deficits, and incapable of returning to their employment were categorised as having poor results.

Comparisons between groups were made using Fisher's exact test.

\section{Results}

Fourteen patients dropped out of the study, six from the treated and eight from the placebo group. Of the six patients withdrawn from the treated group four should have been excluded initiallythree were over 65 years old and one turned out to be suffering from trauma-one was withdrawn owing to a heart rate in the 30s (asymptomatic) and the other was withdrawn because of poor compliance (this patient later died). Of the eight dropouts in the placebo group, four should have been excluded initially and were therefore withdrawn -one was too old, one had suffered trauma, and two had a history of asthma. Of the other four withdrawals, one developed arrhythmias, one did not comply with treatment, and two deteriorated considerably after operation (one of whom died). The following results related to the 134 (68 treated and 66 controls) who completed the study.

Table I shows the distribution of aneurysms in the two groups of patients. There was a high proportion of aneurysms of the anterior communicating and internal carotid arteries in the treated group and a higher number of multiple aneurysms in the controls.

Table II shows the clinical gradings of patients at admission and after four weeks. Those in grades 1 and 2 are regarded as having good results. The table shows that the clinical states of the two groups of patients on admission are fairly comparable, if anything the treated group being slightly worse. After four weeks a trend was shown in favour of the patients in the treated group $(p=0 \cdot 11)$. If the patients with aneurysms are considered separately (table III) the results again show a trend in favour of the treated group $(p=0 \cdot 11)$. If men and women with aneurysm are separated the results at four weeks show some disparity (table IV) despite comparable gradings on admission.
The differences in the outcome for women with aneurysms between the treated and control group is almost significant $(p=0.053)$, though the gradings of the two groups were similar on admission.

TABLE I-Distribution of aneurysms in treated and control groups

\begin{tabular}{lcc}
\hline & $\begin{array}{c}\text { Treated* } \\
(\mathrm{n}=68)\end{array}$ & $\begin{array}{c}\text { Control } \dagger \\
(\mathrm{n}=66)\end{array}$ \\
\hline Anterior communicating & 19 & 11 \\
Internal carotid & 18 & 12 \\
Middle cerebral & 10 & 12 \\
Multiple & 4 & 10 \\
Vertebrobasilar & 1 & 2 \\
Others & 0 & 3 \\
Arteriovenous malformation & 4 & 2 \\
No aneurysm & 12 & 14 \\
\hline
\end{tabular}

${ }^{*}$ Mean age 46.6 years. $\dagger$ Mean age 46.4 years.

TABLE II-Neurological grading of all patients at admission and at four weeks in treated and control groups

\begin{tabular}{|c|c|c|c|c|c|c|}
\hline \multirow{2}{*}{ Grade } & \multicolumn{3}{|c|}{ Treated $(n=68)$} & \multicolumn{3}{|c|}{ Control $(n=66)$} \\
\hline & Admission & $\begin{array}{l}\text { Four } \\
\text { weeks }\end{array}$ & Results & Admission & $\begin{array}{l}\text { Four } \\
\text { weeks }\end{array}$ & Results \\
\hline $\begin{array}{l}1 \\
2\end{array}$ & $\begin{array}{l}23 \\
14\end{array}$ & $\left.\begin{array}{r}36 \\
9\end{array}\right\}$ & $\begin{array}{c}\text { Good } \\
(n=45)\end{array}$ & $\begin{array}{l}28 \\
12\end{array}$ & $\left.\begin{array}{r}31 \\
3\end{array}\right\}$ & $\begin{array}{c}\text { Good } \\
(n=34)\end{array}$ \\
\hline $\begin{array}{l}3 \\
4 \\
5 \\
6 \\
\text { Death }\end{array}$ & $\begin{array}{r}0 \\
23 \\
3 \\
5\end{array}$ & $\left.\begin{array}{r}6 \\
4 \\
3 \\
0 \\
10\end{array}\right\}$ & $\begin{array}{c}\text { Poor } \\
(n=23)\end{array}$ & $\begin{array}{r}1 \\
18 \\
6 \\
1\end{array}$ & $\left.\begin{array}{r}14 \\
3 \\
1 \\
0 \\
14\end{array}\right\}$ & $\begin{array}{c}\text { Poor } \\
(\mathrm{n}=32)\end{array}$ \\
\hline
\end{tabular}

TABLE III-Neurological grading of patients with aneurysm (shown by angiography) at admission and at four weeks

\begin{tabular}{|c|c|c|c|c|c|c|}
\hline \multirow{2}{*}{ Grade } & \multicolumn{3}{|c|}{ Treated $(\mathrm{n}=52)$} & \multicolumn{3}{|c|}{ Control $(n=50)$} \\
\hline & Admission & $\begin{array}{c}\text { Four } \\
\text { weeks }\end{array}$ & Results & Admission & $\begin{array}{r}\text { Four } \\
\text { weeks }\end{array}$ & Results \\
\hline $\begin{array}{l}1 \\
2\end{array}$ & $\begin{array}{l}19 \\
10\end{array}$ & $\left.\begin{array}{r}26 \\
6\end{array}\right\}$ & $\begin{array}{c}\text { Good } \\
(n=32)\end{array}$ & $\begin{array}{r}20 \\
9\end{array}$ & $\left.\begin{array}{r}19 \\
3\end{array}\right\}$ & $\underset{(\mathrm{n}=22)}{\text { Good }}$ \\
\hline $\begin{array}{l}3 \\
4 \\
5 \\
6 \\
\text { Death }\end{array}$ & $\begin{array}{r}0 \\
19 \\
1 \\
3\end{array}$ & $\left.\begin{array}{r}4 \\
3 \\
3 \\
0 \\
10\end{array}\right\}$ & $\begin{array}{c}\text { Poor } \\
(n=20)\end{array}$ & $\begin{array}{r}1 \\
14 \\
5 \\
1\end{array}$ & $\left.\begin{array}{r}12 \\
1 \\
1 \\
0 \\
14\end{array}\right\}$ & $\begin{array}{c}\text { Poor } \\
(n=28)\end{array}$ \\
\hline
\end{tabular}

TABLE IV-Neurological results in all patients with aneurysm at four weeks according to sex

\begin{tabular}{|c|c|c|}
\hline & Treated & Control \\
\hline $\begin{array}{l}\text { Women: } \\
\text { Good result } \\
\text { Poor result }\end{array}$ & $\begin{array}{l}24 \\
11 \text { (4 deaths) }\end{array}$ & $\begin{array}{l}15 \\
19 \text { (11 deaths) }\end{array}$ \\
\hline $\begin{array}{l}\text { Men: } \\
\text { Good result } \\
\text { Poor result }\end{array}$ & 8 (6 deaths) & 7 (3 deaths) \\
\hline
\end{tabular}

No patient developed a severe medical complication attributable to $\mathrm{N}$ the medication. There were no cases of cardiac failure, hypotension, or $N$ asthma. One patient who developed an extreme sinus bradycardia $(30-32 / \mathrm{min})$ was withdrawn during the first week on medication but was subsequently found to be in the treated group. The mean heart rate over the three-week trial period was $65.8(\mathrm{SEM} \pm 1.45)$ \& beats/min on drugs and $73.8(\mathrm{SEM} \pm 2.53)$ on placebo $(\mathrm{p}<0.005)$.

Sixteen patients suffered recurrent haemorrhages, 10 in the treated $T_{T}$ group and six controls; this slight excess in the treated group is not

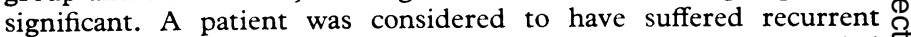
haemorrhage if a sudden deterioration occurred and was accompanied $\frac{\mathbb{D}}{D}$ by evidence of further haemorrhage on CT scan or lumbar puncture $\sigma$ or if there was evidence of fresh bleeding at necropsy. More gradual $<$ deterioration was regarded as being due to cerebral vasospasm, with of 10 occurring in the treated and 20 in the control group. Clinical deteriorations due to spasm occurred significantly more often in the control group $(\mathrm{p}<0.05)$. 
More patients with aneurysm underwent operation in the treated group $(37(71 \%) v 26(52 \%) ; \mathrm{p}=0.066)$; the delay to operation was not significantly different in the two groups (13.2 days from bleeding in treated group, 11.8 in controls). Two patients underwent carotid ligation and the rest clipping or wrapping of the aneurysm itself. One patient in the treated group was regarded as suitable for surgery but declined operation. Outcome after surgery also favoured the treated group, with good results in $29(78 \%)$ compared with only $14(53 \%)$ controls $(\mathrm{p}=0.030)$. Thus the treated group were more likely to undergo operation and those who did so fared significantly better than control patients.

Before the start of the trial the anaesthetists expressed some reservations about the theoretical problems of controlling blood pressure in patients having adrenergic blockade; once they had become accustomed to the use of these drugs, however, they felt their control over blood pressure was, if anything, smoother than in the control patients.

A total of 24 patients (10 treated, 14 controls) admitted to the trial died within four weeks: all these patients had aneurysms. Eight treated patients died of recurrent haemorrhage (shown at necropsy) as opposed to only four controls. Only two treated patients died after a progressive nuerological deterioration, consistent with spasm, compared with 10 controls. Although these figures are small they are a further indication of an encouraging trend. When results of patients in grades 1 and 2 at time of operation were compared they again favour the treated group. Of the 32 grade 1 and 2 patients in the treated group 28 had good results, four had poor results and one died; of the 20 controls 12 had good results, eight bad, and three died $(\mathrm{p}=0.040)$.

Table V shows the outcome of the assessment at one year. Five further patients had died (since assessment at one month), two with recurrent haemorrhage (one in each group), and three from medical complications after being left with severe neurological deficits. If the

TABLE $\mathrm{V}-$ Results at one year (Good =able to work; disabled $=$ unable to work)

\begin{tabular}{|c|c|c|c|c|c|c|c|}
\hline & \multicolumn{3}{|c|}{ Treated } & \multicolumn{3}{|c|}{ Control } & \multirow[b]{2}{*}{ p Value } \\
\hline & Good & Disabled & Dead & Good & Disabled & Dead & \\
\hline $\begin{array}{l}\text { All patients: } \\
\text { Women } \\
\text { Men }\end{array}$ & $\begin{array}{l}50 \\
35 \\
15\end{array}$ & $\begin{array}{l}6 \\
5 \\
1\end{array}$ & $\begin{array}{r}12 \\
5 \\
7\end{array}$ & $\begin{array}{l}36 \\
21 \\
15\end{array}$ & $\begin{array}{r}13 \\
5 \\
8\end{array}$ & $\begin{array}{r}17 \\
13 \\
4\end{array}$ & $\begin{array}{l}0.030 \\
0.036 \\
0.569\end{array}$ \\
\hline $\begin{array}{l}\text { Men } \\
\text { All patients with } \\
\text { aneurysm: } \\
\text { Women } \\
\text { Men }\end{array}$ & $\begin{array}{r}15 \\
35 \\
26 \\
9\end{array}$ & $\begin{array}{l}1 \\
6 \\
5 \\
1\end{array}$ & $\begin{array}{r}7 \\
11 \\
4 \\
7\end{array}$ & $\begin{array}{r}15 \\
24 \\
17 \\
7\end{array}$ & $\begin{array}{l}8 \\
9 \\
4 \\
5\end{array}$ & $\begin{array}{r}4 \\
17 \\
13 \\
4\end{array}$ & $\begin{array}{l}0.569 \\
0.071 \\
0.049 \\
0.731\end{array}$ \\
\hline
\end{tabular}

disabled and deceased patients are combined the difference between the two groups show greater significance than at one month, in that the overall group and the women also show a significant difference between treatment and controls $(p<0.05)$ : for the group with aneurysm the $p$ value $=0.071$. Once again there is little difference between the outcome of the treated and control groups of men, although the number of men is relatively small.

\section{Discussion}

Our findings suggest that adrenergic blockade confers some benefit in subarachnoid haemorrhage, though the mode of action is not clear. It would be attractive to suggest that adrenergic blockade alleviated spasm since adrenergic innervation of cerebral vessels has been shown by fluorescent and electron microscopic studies. ${ }^{910}$ Furthermore, repeated spasm in experiments has been shown to lead to a depletion of catecholamine stores. ${ }^{11}$ Adrenergic blockade reduced spasm in cats ${ }^{12}$ and rhesus monkeys, ${ }^{11}$ and improvement was reported in a few patients who had clinical evidence of spasm after surgery and who then received an intracarotid injection of phenoxybenzamine. ${ }^{13}{ }^{14}$ More recent experimental and clinical work, however, suggests that no appreciable changes of flow occur with alpha-blockade in subarachnoid haemorrhage. ${ }^{315}$ Preliminary flow studies in our current series using xenon clearance and which are outside the scope of this paper, did not suggest any improvement in flow.

A further theoretical advantage of alpha-blockade would be to reduce the tendency to pulmonary oedema. Patients with subarachnoid haemorrhage occasionally develop fulminating pul- monary oedema. Moreover, a high proportion of patients dying after aneurysm rupture have evidence of pulmonary oedema at necropsy, even when this may not have been suspected clinically. ${ }^{16}$ By decreasing afterload, alpha-blockade would reduce the incidence of pulmonary oedema leading to a small, but possibly clinically important, improvement in partial oxygen pressure.

A smoothing of the blood pressure might be expected to reduce the rate of recurrent haemorrhage in the patients treated with adrenergic blockade, who show less variability in their blood pressure. ${ }^{17}$ Despite this, the incidence of recurrent haemorrhage was in fact slightly higher in the treated group in this study. Previous work has suggested that recurrent haemorrhage is more likely to occur at lower intracranial pressure. ${ }^{18} \mathrm{~A}$ reduction in intracranial pressure achieved by the drugs may increase the liability to recurrent haemorrhage, though we have no evidence of this in the present study. Antifibrinolytic agents might have reduced this trend, though a recent report of the aneurysm co-operative study ${ }^{19}$ in a comparable series of patients treated with antifibrinolytic agents showed results similar to those of our control group.

Patients with high catecholamine output after subarachnoid haemorrhage have been shown to have a less favourable outcome. ${ }^{5}$ Furthermore, there was a correlation between catecholamine concentrations and electrocardiographic changes, some of which were consistent with ischaemic lesions and may be reversed with propranolol. ${ }^{8}$ At necropsy, a high proportion of these patients have microinfarcts in the myocardium. In a group of six patients who died while undergoing treatment with adrenergic blockade, no myocardial lesions could be found, though these patients were shown to have hypothalamic lesions of a type often associated with the myocardial lesions. ${ }^{17}$ Thus adrenergic blockade appears to prevent the myocardial lesion while hypothalamic lesions are unaffected.

A more recent postmortem study has suggested that women with subarachnoid haemorrhage have a higher incidence of myocardial lesions than men. ${ }^{20}$ This suggests that women may have a more severe catecholamine response than men. Our findings may reflect this difference rather than being a consequence of a fixed dose regimen.

Beta-blocking agents, such as propranolol, normally reduce plasma renin activity. Patients with high plasma renin activities tend to have a poorer outcome than those with low or normal activities. $^{2122}$ To what extent the rise in renin activity is related to clinical deterioration is unknown, but this suggests a further protective action of adrenergic blockade. Both propranolol and alpha-blocking agents given by intracarotid infusion reduced cerebral oxygen requirements in a series of patients with stroke or cerebral ischaemia. ${ }^{23}$ This reduction may be due to the prevention of uncoupling of oxidative phosphorylation, normally caused by catecholamines. A small reduction in oxygen requirements in a patient with reduced cerebral blood flow after subarachnoid haemorrhage may be of great importance, and the benefit would be greater in patients with high catecholamines concentrations. Reduction in oxygen requirement may be an important factor in the treated patients in the present series. Certainly fewer mice exposed to acute hypoxia suffered hypoxic deaths when pretreated with propranolol ${ }^{24}$ (in contrast to beta-blockers with intrinsic sympathomimetic activity). Enzyme (creatinine kinase) leakage from anoxic tissue is greatly decreased by pretreatment with propranolol and mitochondrial function is preserved. ${ }^{25}$ In addition propranolol shifts the oxygen dissociation curve to the right so making more oxygen available to the tissues ${ }^{26}$ (this action is unlikely to be clinically relevant at the doses of propranolol used in this study).

The finding that improvement in results in the treated group is more significant at one year than at one month supports the idea that adrenergic blockade in some way confers a degree of protection during the period of insult, thus giving greater scope for recovery once this period has passed.

With the findings of the improved outcome after surgery and our concern over the rebleeding rate, we propose to continue the 
trial, and to operate on a random proportion of patients within five days of haemorrhage while maintaining beta-adrenergic blockade.

\section{Addendum}

The above study was extended to examine the effects of early operation in patients taking two tablets of long-acting propranolol daily (no alpha-blockade). Patients were randomised in singleblind fashion into one of three groups: propranolol-early operation: propranolol-late operation; and placebo-late operation. Seventy patients were added to the original 134,111 in the treated and 93 in the placebo group. In the treated group there were 80 good and 31 poor results compared with 48 good and 45 poor results $(p=0.003)$ in the placebo group at four weeks. There were significantly fewer deaths $(13 \vee 21$ ( $\mathrm{p}=$ $0.026)$ ) in the treated than in the placebo group.

Benefit would appear to accrue from beta-blockade rather than alpha-blockade, as the good (including deaths) results appeared equally in the first 100 patients (treatment alpha-blockade plus beta-blockade) and the next 104 patients (treatment betablockade alone).

We thank J Bartlett and R Maurice-Williams for allowing their patients to enter the trial, Professor Healy and Mr S Ellis for statistical advice, and Dr D Burley for supplying phentolamine and placebo tablets.

\section{References}

1 Allen GS, Henderson LM, Chou SN, French LA. Cerebral arterial spasm I. In vitro contractile activity of vasoactive agents in canine basilar and middle cerebral arteries. $\mathcal{F}$ Neurosurg $1974 ; 40: 433-41$.

${ }^{2}$ Allen GS, Henderson LM, Chou SN, French LA. Cerebral arterial spasm II. In vitro contractility of serotonin in human serum and CSF in canine basilar artery and its blockade by methysergide and phenoxybenzamine. f Neurosurg $1974 ; \mathbf{4 0}: 442-50$.

3 Starling LM, Boulin DJ, Graham-Smith DG, Adams CBT, Gye RS. Response of isolated human basilar arteries to $5 \mathrm{HT}$, noradrenaline, serum, platelets and erythrocytes. $\mathcal{F}$ Neurol Neurosurg Psychiatry 1975; 38:650-6.

${ }^{4}$ Osaka K. Prolonged vasospasm produced by the breakdown product of erythrocytes. $\mathcal{f}$ Neurosurg 1977;47:403-11.

5 Neil-Dwyer G, Cruickshank JM, Stott A, Brice J. The urinary catecholamine and plasma cortisol levels in patients with subarachnoid haemorrhage. 7 Neurol Sci 1974;22:375-82.
6 Armstrong FS, Hayes GT. Segmental cerebral arterial contraction associated with phaeochromocytoma. F Neurosurg 1961;18:843-6.

7 Peerless SJ, Yasargil M. Adrenergic innervation of the cerebral blood vessels of the rabbit. $\mathcal{I}$ Neurosurg $1971 ; 35: 148-54$.

${ }^{8}$ Cruickshank JM, Neil-Dwyer G, Lane J. The effects of oral propranolol upon the ECG changes occurring in subarachnoid haemorrhage. Cardiovasc Res 1975;9:236-45.

${ }^{9}$ Nielsen KC, Owmen C. Adrenergic innervation of pial arteries related to the Circle of Willis in the cat. Brain Res $1967 ; 6: 773-6$.

10 Nelson E, Rennals M. Innervation of intracranial arteries. Brain 1970;93 : 475-90.

${ }^{11}$ Frazer RAR, Stein BM, Barrett RE, Pool JL. Noradrenergic mediation of cerebrovascular spasm. Stroke 1970;1:356-62.

12 Flamm ES, Yasargil MG, Ransahoff J. Alteration of experimental cerebral vasospasm by adrenergic blockade. F Neurosurg 1972;37:294-301.

13 Cummins BH, Griffiths HB. Intracarotid phenoxygenzamine for cerebral arterial spasm. Br Med $\mathcal{F} 1971 ; \mathrm{i}: 382-3$.

${ }^{14}$ Handa J, Matsuda $M$, Ohtsubo K, Handa H. Effect of intracarotid phenoxybenzamine on cerebral blood flow and vasospasm: a clinical study. Surg Neurol 1973;1:229-32.

15 White RP, Huang SP, Harper AA, Robertson JT. Experimental assessment of phenoxybenzamine in cerebral vasospasm. $\mathcal{F}$ Neurosurg 1979; 50:158-63.

16 Weir BK. Pulmonary oedema following fatal aneurysm rupture. $\mathcal{F}$ Neurosurg 1978;49:502-7.

${ }^{17}$ Neil-Dwyer G, Walter P, Cruickshank JM, Doshi B, O'Gorman P. Effects of propranolol and phentolamine on myocardial necrosis after subarachnoid haemorrhage. $\mathrm{Br}$ Med 7 1978; ii :990-2.

18 Nornes $\mathrm{H}$. The role of intracranial pressure in the arrest of haemorrhage in patients with ruptured intracranial aneurysm. I Neurosurg 1973;39: 226-34.

19 Adams HP, Kassell NF, Turner JC, Nibbelink DW, Sahs AL. Early management of aneurysmal subarachnoid haemorrhage. 7 Neurosurg $1981 ; \mathbf{5 4}: 141-5$

${ }^{20}$ Doshi R, Neil-Dwyer G. A clinicopathological study of patients following subarachnoid haemorrhage. F Neurosurg 1980;52:295-301.

21 Neil-Dwyer G, Cruickshank JM. Plasma renin and angiotensin II levels in subarachnoid haemorrhage. 7 Neurol Sci 1974;23:463-71.

${ }_{22}$ Neil-Dwyer G, Walter P, Shaw HJH, Doshi R, Hodge M. Plasma renin activity in patients after a subarachnoid haemorrhage-a possible predictor of outcome. Neurosurgery 1980;7:578.

${ }^{23}$ Meyer JS, Okamoto S, Shimazu K, Kato A, Okuchi T, Sari A, Ericsson AD. Cerebral metabolic changes during treatment of subacute cerebral infarction by alpha- and beta-adrenergic blockade with phenoxybenzamine and propranolol. Stroke $1974 ; 5: 180-95$.

24 Krupinska J. Beta-adrenergic receptor blockade as a protection against the death of hypoxia. Polf Pharmacol Pharm 1973;23:145-50.

${ }_{25}$ Nayler WG, Fassold E, Yepez C. Pharmacological protection of mito chondrial function in hypoxic heart muscle: effect of verapamil, propranolol, and methylprednisolone. Cardiovasc Res 1978;12:152-61.

26 Trembath PW, Taylor EA, Turner P, Roberts M, Cole P, Amess J. The haemoglobin-oxygen dissociation curve: in vivo and in vitro effects of five beta-adrenoceptor antagonists and lignocaine. Br 7 Clin Pharmacol $1981 ; 11: 19-24$.

(Accepted 15 March 1982)

\section{OF CONSUMPTIONS.}

A Consumption is a wafting or decay of the whole body from an ulcer, tubercles, or concretions of the lungs, an empyema, a nervous atrophy, or a cachexy.

Dr. ARBUthot obferves, that in his time confumptions made up above one-tenth part of the bills of mortality in and about London. There is reafon to believe they have rather increafed fince; and we know for certain, that they are not lefs fatal in fome other towns of England than in London.

Young perfons, betwixt the age of fifteen and thirty, of a flender make, long neck, high fhoulders, and flat breafts, are moft liable to this difeafe.

CONSUMPTIONS prevail more in England than in any other part of the world, owing perhaps to the great ufe of animal food and malt-liquors, the general application of fedentary employments, and the great quantity of pit-coal which is there burnt; to which we may add the perpetual changes in the atmolphere, or variablenefs of the weather.

CAUSES. - It has already been obferved, that an inflammation of the breaft often ends in an importhume: Confequently whatever difpofes people to this difeafe, muft likewife be confidered as a caufe of consumptions.
OTHER difeafes, by vitiating the humours, may likewife occafion confumptions; as the fcurvy, the fcrophula, or king's evil, the venereal difeafe, the afthma, fmall-pox, meafles, \&c.

As this difeafe is feldom cured, we fhall endeavour the more par- o ticularly to point out its caufes, in order that people may be enabled to avoid it. Thefe are:

- CONFINED or unwholefome air. When this fluid is impregnated with the fumes of metals or minerals, it proves extremely hurtful N to the lungs, and often corrodes the tender veffels of that neceffary organ.

-VIOLENT paffions, exertions, or affections of the mind; as grief, difappointment, anxiety, or clofe application to the ftudy of abftrufe arts or fciences.

-GREA T evacuations; as fweating, diarrhœas, diabetes, exceffive venery, the fluor albus, an overdifcharge of the menftrual flux, giving fuck too long, \&c.

- THE fudden ftoppage of cuftomary evacuations; as the bleeding piles, fweating of the feet, bleeding at the nofe, the menfes, iffues, ulcers, or eruptions of any kind.

(Buchan's Domestic Medicine, I786.)

.

